\title{
CAI: Goals and perspectives: Computer users' group panel discussion
}

\author{
M. PAVEL and DORIS AARONSON \\ New York University, New York, New York 10003
}

\begin{abstract}
This report of the users' group meeting contains a condensed version of a panel discussion of general issues involving computer-assisted instruction (CAI) systems. The discussants were asked to comment on the goals of the CAI efforts and the past accomplishments and future of computer systems in education.
\end{abstract}

As this year's Computers in Psychology program contained many papers on specific computer-assisted instruction (CAI) projects, a panel discussion was organized to entertain more general issues related to the development and implementation of CAI systems. The panel members were selected, one from each of several earlier sessions, to comprise a group having a wide variety of backgrounds and experiences: N. John Castellan, Indiana University; Robert Holt, George Mason University; C. Michael Levy, University of Florida at Gainesville; James E. Spivey, University of Kentucky; and, as moderator, Misha Pavel, New York University.

As a historical note, this session is the first truly joint computer users' session for Computers in Psychology. During the past several meetings, the various special interest groups gradually combined, reflecting the fact that a typical laboratory uses a variety of machines. This is also true of the CAI projects.

The following report of the users' group discussion is based on an audiotape recording that we conservatively edited to reduce the amount of text to the allotted space. Thus, we apologize for any inadvertent distortions of the content or style.

\section{PANEL DISCUSSION}

Pavel: The primary reason for organizing this panel discussion is the sudden increase in the number of people interested in CAI. This is exemplifed by the extraordinarily large number of papers related to CAI at this conference. In fact, $41 \%$ of all papers presented today dealt with CAI. The basic idea of CAI is not new. Ever since computers became available to the public and to educators, the notion of CAI has existed. I think most people will agree that CAI can be a very useful tool or at least has potential. However, when one examines its actual application, it seems to be rather limited. Certainly, one is not likely to see much utilization of CAI systems beyond the small groups of workers involved in the development of these systems. Why is this so? In part, it is because of the great complexity of the endeavor. It appears that this task may be more complicated than many highly technical programs such as, for example, the NASA project of going to the moon. At least in the moon projects NASA had a clear goal or target. But in CAI, even the goals and objectives are difficult to specify clearly.

In addition to the problem of direction, CAI projects are complex because of their interdisciplinary nature. Developers of CAI systems are forced to solve a large number of problems from many different areas. Examples of some of these are shown in Figure 1. One of the difficulties concerning education is the development of an approach for evaluating any instructional system. The evaluation techniques and criteria could then be applied to the design of courseware together with the knowledge of the principles governing the learning process. The more sophisticated systems face the problem of representation of the knowledge to be taught.

New developments in technology are required in order to solve problems specific to the design and operation of CAI systems, involving software engineering and interfacing machines with people. The problems in economics and politics must be at least partially solved before any effort can even begin. Today, we have heard papers on some of these issues. The issues of economics seem to be easier to deal with than those of politics. The issues of funding are only part of the political picture. Equally important is the reluctance on the part of universities even to support some of this work emotionally.

To clarify the current situation in CAI, I would like to start off this discussion by asking the experts on our panel why CAI has not been implemented more widely and why its success has not been more obvious.

Levy: When I got started, it was very expensive to get into the CAI business. Eight or 9 years ago, I spent $\$ 35,000$ to buy one computer to run one laboratory course and I spent another

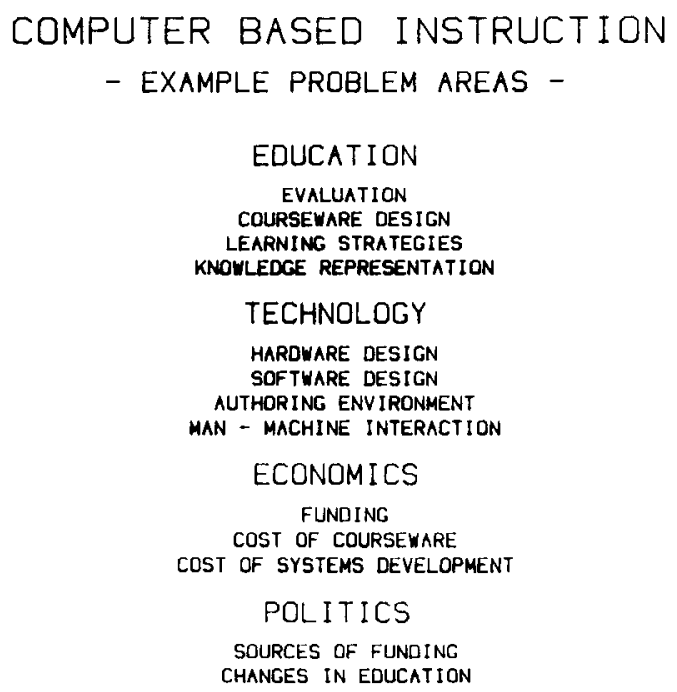

Figure 1. 
$\$ 30,000$ to develop the software for it. I think it's only been the last few years that we've had relatively inexpensive equipment and some supply of software. So, there hasn't yet been enough time for the now affordable systems to spread widely. But, I think CAI is growing.

Further, I think CAI is going to spread much more slowly than the use of computer-based laboratory research did because it's a lot of work to get CAI off the ground. Even if you buy the software off the shelf, it costs another order of magnitude or two above that to develop your particular courseware. In most places, you are not rewarded for going that route. Major universities do not give any payoff for that.

Spivey: Following up on Levy's last statement, I know that when I was in graduate school, I learned very early that you don't let people know that you have abilities in statistics, computers, or instrumentation, or you will end up being used by many others in the department. People who get too involved in computers and instrumentation lose their jobs or leave psychology entirely. Many faculty were terminated who had made tremendous contributions to CAI. You must make a major political effort ahead of time to convince the administration to reinforce those individuals who invest time in CAI. As we all know, there are only a finite number of hours in the day, and time spent on CAI detracts from time on research publications. Tenured faculty have patted junior faculty on the back for not getiing involved in CAI projects and have complimented them for making a wise decision about their time allocation.

To really get into this enterprise, you have to be concerned with students, and with the quality of your course, which CAI will serve. You must focus on the goals of CAI and not lose the forest for the trees. We all know people who get into CAI and devote a disproportionate amount of time to the details of instrumentation and lose tract of the educational goals.

Pavel: Why is it difficult to convince the administration that it is worthwhile for the faculty to spend time on CAI?

Spivey: One reason is that more evaluation is needed to demonstrate the efficacy of CAI. A lot of people are not convinced that it really does that much good. They think the students are playing games.

Holt: I want to disagree with one thing Spivey said. My wife and I have done evaluation research on the PLATO system at the University of Illinois. It is remarkable how difficult it is for people to consider the CAl environment objectively. The political issues on Pavel's display are quite important and often don't seem to connect directly with the evidence that you may have regarding the effectiveness of a CAI system. Even when the cost was not a factor, we had trouble gaining acceptance and implementation, at least in the psychology department. (It was better accepted by foreign language and education departments.) It was a typical case study of endangering the tenure of the psychologist working on the system. He did not get tenure and left for another environment.

Although we have often been quite creative in implementing CAI on the computer, we have often failed in product evaluation and design prior to developing the computer programs. Evaluation of implementation approaches before designing a CAI lesson would make it more likely to succeed in a real environment. For example, a "critical incident testing" of CAI material on both the best and worst students would be useful. Too often, we base our initial evaluation on the best or most motivated students, those who come in voluntarily. We should develop a more optimal design of material prior to the final implementation, through an iterative procedure of user editing. This would involve only a small number of students but would use successive samples, modifying the materials for each sample. Finally, we should bring together actual users, of ten students, for a focused group discussion of the pros and cons.
Castellan: I can only echo some of the earlier concerns about one of the biggest impediments. That is an absence of a reward structure. In both large and small institutions, developing computer-based modules is not what brings individual professional payoff to the faculty. Developing one CAI course is like writing an entire textbook, not a single article. But what gets people promoted is a series of related articles. I have found it difficult in discussing these issues with university administrators. CAI is viewed as "teaching" as opposed to "research," and teaching is not rewarded in the evaluations for promotions.

In the past, I have offered to write a letter of support to the department chairperson for people submitting CAI programs to CONDUIT who are up for promotion or tenure. I state that the CAI project has been evaluated through a peer review process, just like an article submitted for publication. That kind of support, coming from outside the candidate's institution, can sometimes help. Further, in most universities, getting outside funding, getting NSF "CAUSE" grants have not counted for much. Administrators state "anyone can get those grants, they are easy to get; there isn't much competition." But, in fact, the NSF ISEP and NSF CAUSE grants are far more competitive than research grants from NIMH psychology sections in terms of the numbers submitted and those funded. That kind of information can be helpful for people being evaluated for promotion.

In sum, a major problem we are faced with is an indifference to the quality of education: It has nothing to do with the fact that it is CAI. A second issue is the lack of knowledge of what is really involved: CAI is counted as just a single article, whereas it actually involves far more time. So, PR is the biggest job we have to do.

Spivey: In addition, there is an "antiengineering" or "antitechnology" mentality in psychology. But, the micros are helping to reduce those problems. They don't look as threatening, and they are called "personal" computers. Contrary to our expectations, the undergraduates were not very threatened by the equipment. But good graduate teaching assistants of ten resigned from the course when the equipment arrived, and faculty had even bigger problems with equipment utilization.

Aaronson: In relation to the imbalance of rewards for CAI and research, it is striking that CAI is not linked hand in hand with research. When CAI began in the lab of Suppes and Atkinson at Stanford, the psychologists there used the students' CAI performance data to test theoretical models of learning, memory, and problem solving. Today there is a marked separation in psychology departments between curriculum development and research activities. Perhaps some of the panel members can tell us why these two areas have not been interrelated.

Castellan: I think many people are beginning to develop successful joint programs. But they are not yet spilling over into the actual production in a classroom environment. There is also work at the precollege level.

The issue of educational evaluation is difficult, but it is not whether a computer is better. It may be whether a computer is cheaper, and we will have a very hard time fighting against that argument. Based on information learned per dollar, the lecture format will beat out almost all other techniques, including CAI. But university libraries are more expensive than computers: The estimates are that it costs $\$ 20$ to check a book out. What would happen if we told faculty to charge extra for each book their students checked out of the library?

Rothkopf: I want to draw your attention to the fact that we should consider the 30 years of experience of experimental psychologists trying to have some impact on instruction. The real culprit is not so much the reward structure in the universities, but the reluctance of university professors to consider the goals of their courses, to systematically analyze and measure these goals, and to be "results oriented." Both university admin- 
istrators and professors resent being results oriented. Why should someone whose work is completely opaque to results worry about the installation of better procedures?

Earlier work has shown that it is very difficult to develop good instruction as a "cottage industry." You can't accomplish anything with only $\$ 30,000$. The actual instructional development with the kinds of iterative procedures Holt describes is tremendously expensive, several thousand dollars per hour of instruction. Rather, you must have a cooperation among people to raise a lot of moncy and systematically produce instructional material. However, the main point is that people aren't willing to state the goals of instruction objectively and then to measure the results. If you don't do that, who can determine what efforts are having any impact on the world and who can determine whether the instruction works? It seems that few people on this panel started by saying that I want to achieve a particular goal, and the computer is a tool toward that end. Most people say, "I have a computer; let's see if we can put it to work in instruction."

Levy: In all fairness, that first \$35.000 PDP came forth because I had a plan for a laboratory course in experimental psychology. We had a course on the books that had not been taught for years because we had a room full of equipment from my mentor's days that didn't work, and my university could not come up with the funds 10 outfit a complete traditional laboratory. So I said there might be a way for a smaller total investment, a smaller university investment, and less space if we got a box that could pretend to be a tachistoscope or a controller for learning experiments, etc., and to do other things in its spare time as well. So, I was driven by a specific goal. An impressed department chair then impressed our dean, who then impressed our vice-president. After two prior failures to get through NSF successful CAUSE proposals, these administrators asked the psychology department to develop a successful proposal. So, a larger CAI project was formed as a goal.

Rothkopf: I withdraw what I said, with respect to you.

Spivey: A lot of people wish that we had considered careful evaluation $10-15$ years ago, as is now required by NSF. But there is another indicator of a successful course: student enrollment. In fact, our course now has only $50 \%$ psychology majors; $25 \%$ are now from computer science, and another $25 \%$ are from business and other departments. The service role of the course, its popularity, and the prestige for psychology are now growing because of the CAI element.

Sidel: I want to make three comments. Iirst, I once read a history of accountability of the German general to his staff. Much to my surprise, I found that, typically, the German generals were against starting the war. The reason was that they could lose it. With respect to the introduction of the CAI systems, or any other kind of technology, into learning as well as other environments, as cynical as this sounds, we have to convince the relevant people that they will not be held accountable for their acts.

The second point I want to make is that based on an old article by Rothkopf: There are convincing arguments by a British experimental psychologist, Patricia Write, about keeping pure and applied research separate.

Thirdly, I want to make a point that "computerphobia" (in faculty, graduate students and the public at large) is the wrong term. A "phobia" is an irrational fear, and fear of CIA has some rational bases in these populations. I've seen a situation where a secretary had to enter information into a machine, and the machine frequently hung up. No one could tell her how to get it to work, and, of course, shc resigned.

Castellan: However, there is another important issue. Successful research laboratories consist of a faculty member who marshals a group of graduate students and as many undergraduates as possible and gets technical people involved. One problem is getting the people and the technicians together. There is of ten a missing ingredient in instructional work, namely, an "instructional specialist." This is an emerging group of experts that are support personnel for instructional development. For example, they might deal with ways to present educational material that are "user friendly." In general, they help faculty develop optimal media for presenting their message. If you publish a book, the publisher provides artists, photographers, graphics specialists, and copy editors. That's the kind of person that we critically need for developing new educational ideas in the university.

Spivey: The idea of outside technical support is something the granting agencies are becoming familiar with also. After our CAUSE grant was turned down, we added external evaluators. That served our needs, convinced NSF that we were being objective and honest about the results of what we were doing, and helped get the project funded.

Rothkopf: I couldn't disagree more with what Castellan said. I really think that you are reliving a kind of drama that has been relived for the past 30 years. That drama deals with the belief that the surface features of the display are pedagogically important attributes. You believe that the production-the format, the layout -is going to bring you many "goodies." But you are going to be disappointed. The pedagogically relevant aspect comes right out of experimental psychology. It involves a clarification of your goals and a task analysis of what you want to teach. Then, you can try various tricks of organizing the material, of pedagogically arranging it, of using what you know from cognitive psychology to develop these into an effective package. In terms of overall student achievement, and in terms of possibilities for evaluation, that procedure will get you a lot more of the total variance than the "production aesthetics" you are discussing. I don't disagree with you that it is useful to have someone who is good in laying these changes out, but my guess is that only a small proportion of the variance can be attributed to the packaging. It is remarkable what kinds of junk people will tolerate. The best example of that is in television. You can learn just as well from a TV show that has poor display properties as from one that has been edited to absolute perfection.

Spivey: I Have to agree with Castellan. The package in which the fruit is wrapped is very critical. Attention is a precursor to learning. Unless the students attend, they will never learn. The need for at tractiveness is something I don't like any more than you do. But you've got to get and sustain student attention.

Rothkopf: I wish I could agree with you, but there are hundreds of studies in the literature that say that's completely wrong. An example is Macoby et al., a big NSF-supported study on format for science teaching. Their results show that the surface features have relatively minor importance.

Spivey: There's another issue. We're competing with TV. When students look at a screen, they expect it to be interesting. Most TV screens are, including pictures, movement, etc. If students see wall-to-wall text on the screen, they will tune out; we found that out with our initial modules. This aspect proved to be more critical than any of us expected, until we got into CAI.

Audience: One important issue involving the usage of CAI is the fact that the computer provides a new tool and can potentially offer new methods of teaching and new demonstrations. It is too often the case that the CAI systems are used in the same way as traditional educational techniques. Some people run the same experiments that were popular in 1940 , rather than introducing more sophisticated modern approaches such as those of Sternberg or Sperling.

Castellan: We don't want to teach students every fact that has been put forth in psychology. We want to teach them how to think. We don't always want to teach students how to design 
experiments, but to evaluate them critically. It is important to do a task analysis and to determine your goals.

On the other hand, my students, over half of which come from the business school, have increasingly convinced me that marketing is an important factor in education. No one has ever sold a Coke by the way it tastes. Lots of money is spent on the look of the bottle, to gain public attention over that given to Pepsi or Dr. Pepper. Certainly, that's not everything, but you've got to get them to open the bottle. That's why the instructional packaging is critical.

Audience: Maybe we are using CAI in the wrong way in that CAI is not the most effective way of bringing information to the classroom market.

Holt: What was said earlier about the relative cost of CAI vs. lectures is quite valid. Large lectures are most cost-effective. In addition, as Aaronson mentioned in an earlier talk, CAI monitoring by human instructors is still necessary to deal with (1) student motivation, (2) computer crashes, and (3) educational goals. That point is relevant to "computer-managed" instruction, the second component of CAI. This is present in PLATO but not in most CAI systems. I'm referring to a component that guides the student through the system, keeps track of student performance, handles all the overhead for you. This would help in gaining student acceptance of the material. For example, this can enable the student to select for himself the actual program sequence that he wants to develop. Giving students more freedom generally enhances their motivation. Thus, the management aspect of CAI should be seriously considered in implementing an entire system.

Spivey: I would hastily add that CAI is not very expensive with the recent developments in microprocessors.

Audience: One of the major impediments to CAI catching on is the lack of marketing of available software. If big publishing companies handled this and sent salesmen to your office monthly, telling you about the latest software packages, CAI would have caught on years ago. 